Thorax (1967), 22, 525.

\title{
Rheumatoid pneumoconiosis \\ A study in colliery populations in the East Midlands coalfield
}

\author{
DAVID C. LINDARS AND DEWI DAVIES \\ From the East Midlands Chest X-ray Unit, National Coal Board, and Ransom Hospital, Mansfield
}

\begin{abstract}
The routine chest radiographs of more than 21,000 miners from 23 unselected collieries in the East Midlands have been used for a study of rheumatoid pneumoconiosis and progressive massive fibrosis (P.M.F.). A broadened radiological concept of rheumatoid pneumoconiosis was used in diagnosis. The prevalence of simple pneumoconiosis categories 1,2 , and 3 was $5.5 \%$, and of P.M.F. $0.59 \%$. There were 55 cases accepted as rheumatoid pneumoconiosis, a prevalence of $0.26 \%$. Thirty-two of these had positive latex fixation or Rose-Waaler tests for rheumatoid factor. The prevalence of P.M.F. was found to increase with increasing simple pneumoconiosis prevalence. A slight correlation between rheumatoid pneumoconiosis and simple pneumoconiosis prevalence was also found, but the bulk of the increase in P.M.F. was due to non-rheumatoid cases. The latter was closely paralleled in incidence by that of category 3 simple pneumoconiosis. Grouped results showed that rheumatoid pneumoconiosis occurred in between $2.3 \%$ and $6.2 \%$ of all men affected by pneumoconiosis. When examined on a geographical basis all areas exhibited a similar prevalence of rheumatoid cases, with the exception of Mansfield, where there was a significant excess. This excess was not significant when serologically positive cases only were considered. The findings are discussed in the light of the auto-immune theory for the development of massive lesions in the lungs of coal miners.
\end{abstract}

The association between coalworkers' pneumoconiosis having a well-defined radiological appearance and rheumatoid arthritis was first noted by Caplan (1953) and subjected to critical epidemiological investigation by Miall, Caplan, Cochrane, Kilpatrick, and Oldham (1953). The population examined by Miall et al. consisted of all miners and ex-miners volunteering for a routine chest radiograph in a Welsh mining valley. Another study by Caplan, Payne, and Withey (1962) was based on a selected series of miners. Several authors have described cases in a variety of dust hazards but not on an epidemiological basis.

In Caplan's original description the lesions were described as multiple, well-defined, round opacities, 0.5 to $5 \mathrm{~cm}$. in diameter, distributed throughout the lung fields. In contrast, the lesions of progressive massive fibrosis (P.M.F.) tended, in the early stages, to be less well defined, more irregular in outline, fewer in number, and to appear in the upper zones. They seldom appeared without a background of category 2 or 3 simple pneumoconiosis, whereas rheumatoid pneumo-

1Present address: Pneumoconiosis Medical Panel, Queen Street, Shefficld coniosis often appeared with slight or absent background.

In time rheumatoid pneumoconiosis became increasingly recognized in people without arthritis, though in many the serum gave positive tests for rheumatoid factor. Lesions less typical than those originally described were also recognized as examples of rheumatoid pneumoconiosis.

Caplan et al. (1962) related the presence of rheumatoid arthritis or positive serum tests to other radiographic appearances in coal miners. They studied two groups.

One group had nodular, discrete round opacities, 0.3 to $1.0 \mathrm{~cm}$. in diameter, varying from a few confined to the upper zones on the one hand to innumerable ones resembling a snowstorm on the other. These lesions were in the main smaller than the ones originally described as rheumatoid pneumoconiosis and, because of their size, could be included in the nodular form of simple pneumoconiosis either category 1,2 , or 3 (I.L.O., 1959), depending on their profusion.

The other group had mixed nodular and irregular opacities - a few round and/or irregular opacities on a background of no pneumoconiosis or category 1 simple pneumoconiosis-particularly 
when there was or had been evidence of cavitation.

They found definite rheumatoid arthritis in about $32 \%$ of such patients and probable or possible rheumatoid arthritis in a further $8 \%$. In those without arthritis but showing these radiological features, the sheep cell agglutination test was positive in $46 \%$. Of those with ordinary P.M.F., $13 \%$ also had positive serum tests. Since it was recognized that some cases of rheumatoid pneumoconiosis progressed through recurrent cavitation, infilling, and extension to a picture radiologically indistinguishable from P.M.F., some further cases of rheumatoid pneumoconiosis, were probably buried in this group, explaining, in part at least, the high rate of positive serum tests.

In this paper we present an epidemiological study of rheumatoid pneumoconiosis based on a survey of colliery populations. We have used this broadened concept of rheumatoid pneumoconiosis, but we have considered those with mixed nodular and irregular opacities irrespective of the background of simple pneumoconiosis.

\section{POPULATION STUDIED}

The collieries, all in the East Midlands coalfield, were visited by a chest $x$-ray unit operating the Periodic $X$-ray Scheme of the National Coal Board. The scheme is described by Rogan (1963), who gives results of the first round of surveys. These show that the prevalence of pneumoconiosis in the East Midlands is much lower than for most other coalfields in Great Britain : only $5.8 \%$ of men radiographed showed evidence of pneumoconiosis, against the Great Britain average of $12 \cdot 1 \%$. The scheme provides for every miner to have a chest radiograph every five years and is now in its second round of surveys.

For this investigation the first 23 collieries visited by the East Midlands $X$-ray Unit in the second round of surveys were chosen. They were visited between January 1964 and May 1965 and comprised a group of collieries in each of the six National Coal Board areas into which the East Midlands coalfield was then constituted. Thus a wide geographical coverage was achieved but the collieries were in no way selected; the order in which they were visited had been determined by the first survey five years earlier.

Participation in the scheme is voluntary, but persuasion is used to boost attendance to the level required for epidemiological study. The collieries surveyed had a total manpower of 23,528 ; of these 21,557 had radiographs, an attendance of
$91 \cdot 6 \%$. Individual colliery attendance varied from $83.0 \%$ to $97.1 \%$, but in two-thirds it was over $90 \%$. For the majority of cases two radiographs, taken at an interval of five years, were available.

\section{METHOD}

Radiographs were read initially by one of us (D. C. L.) for clinical purposes during the course $\omega^{\circ}$ of the survey, and were classified according to the $\overrightarrow{\overrightarrow{2}}$ International Classification of Radiographs of Pneumoconiosis (I.L.O., 1959). From these read- ? ings the prevalence of simple pneumoconiosis and of of cases showing large opacities has been obtained. N Cases not previously diagnosed as P.M.F. were o usually referred to chest clinics to exclude other pathology.

Cases for further study were selected by reviewing together at a later date all radiographs showing P.M.F. or tuberculosis or other abnormality necessitating referral to chest clinics, together with a few, graded as simple pneumoconiosis during clinical reading, but which had been noted at the time as being suggestive of rheumatoid pneumoconiosis because of the nodular character of the opacities. Apart from these, films showing only simple pneumoconiosis were not re-read. It should be noted that P.M.F. is not diagnosed unless at least one opacity measures $1 \mathrm{~cm}$. or more in diameter.

We picked out from these radiographs those with an appearance suggestive of rheumatoid pneumoconiosis, even though, in many cases, the appearances were far from typical. The criterion for selection was the presence of at least one fairly well circumscribed opacity in the lung fields, irrespective of the presence of other less characteristic lesions. At this time information was not available about the clinical state of the subjects. The selected cases were interviewed and examined and blood was taken for serological examination. Radiographs of joints were not taken. The criteria of the Committee of the American Rheumatism Association (1959) were used in assessing the $\tilde{N}$ presence or absence of rheumatoid arthritis, those $N$ conforming to the definite or probable groups being accepted. A single serological test was carried out as a routine (latex fixation at a dilution of $1: 20$ ), but if this was negative the differential agglutination titre (Rose-Waaler test) was estimated on the same specimen (but by a different laboratory) and recorded as positive at a titre of $1: 16$. Only one man achieved this titre when the latex test was negative. Additional information was obtained from chest clinics at which miners were known to have attended. 


\section{RESULTS}

One hundred and seven cases for further study were selected at the initial review of radiographs. Fifty-two were subsequently rejected because the opacities were considered to be due to other causes, as listed in Table I. In 14 we felt that

T A B L E I

DIAGNOSIS IN 52 CASES REJECTED FROM INITIAL SELECTION

\begin{tabular}{|c|c|c|c|c|c|c|}
\hline \multicolumn{5}{|c|}{ Diagnosis } & \multicolumn{2}{|c|}{ No. } \\
\hline $\begin{array}{l}\text { Active tuberculosis } \\
\text { Quiescent or inactive } \\
\text { P.M.F. . } \\
\text { Combined inactive tul } \\
\text { Simple pneumoconios } \\
\text { Sarcoidosis } \\
\text { Bronchial carcinoma } \\
\text { Diagnosis unknown }\end{array}$ & $\begin{array}{l}\text { tuberculosis } \\
\text { berculosis and } \\
\text { is } \\
\ldots \\
\ldots \\
\ldots \\
\ldots \\
\ldots\end{array}$ & $\begin{array}{l}\because \\
\ddot{\text { P.M.F. }} \\
\ldots \\
\cdots \\
\ldots \\
\text {. }\end{array}$ & $\begin{array}{l}\cdots \\
\cdots \\
\cdots \\
\cdots \\
\cdots \\
\cdots\end{array}$ & $\begin{array}{l}\cdots \\
\cdots \\
\cdots \\
\cdots \\
\cdots \\
\cdots\end{array}$ & $\begin{array}{r}4 \\
13 \\
22 \\
2 \\
3 \\
2 \\
1 \\
5\end{array}$ & $\begin{array}{l}\text { (5) } \\
\text { (3) } \\
\text { (2) }\end{array}$ \\
\hline Total & . & . & $\cdots$ & $\cdots$ & 52 & (14) \\
\hline
\end{tabular}

Figures in brackets refer to cases 'not entirely ruled out'.

rheumatoid pneumoconiosis had not been entirely ruled out, but we rejected them in favour of the diagnosis given because of insufficient evidence.

The remaining 55 cases have been accepted as rheumatoid pneumoconiosis, 40 being regarded as 'definite' and 15 as 'probable' (Table II). Two died

T A B L E I I

ASSOCIATION WITH ARTHRITIS AND RESULTS OF A SEROLOGICAL TEST FOR RHEUMATOID FACTOR

\begin{tabular}{c|c|c|c|c|c}
\hline $\begin{array}{c}\text { Rheuma- } \\
\text { toid } \\
\begin{array}{c}\text { Pneumo- } \\
\text { coniosis }\end{array}\end{array}$ & No. & $\begin{array}{c}\text { Arthritis } \\
\text { Only }\end{array}$ & $\begin{array}{c}\text { Arthritis } \\
\text { and } \\
\text { Positive } \\
\text { Serology }\end{array}$ & $\begin{array}{c}\text { Positive } \\
\text { Serology } \\
\text { Only }\end{array}$ & $\begin{array}{c}\text { No } \\
\text { Arthritis, } \\
\text { Negative } \\
\text { Serology }\end{array}$ \\
\hline $\begin{array}{c}\text { Definite } \\
\text { Probable }\end{array}$ & $\begin{array}{c}40 \\
15\end{array}$ & 3 & 14 & 14 & 9 \\
\hline Total & 55 & 4 & 14 & 18 & 19 \\
\hline
\end{tabular}

${ }^{1}$ See text.

before interview and no information is available regarding rheumatoid disease, although other information was obtained from records; they have been included as 'probable' cases. Definite cases showed either (a) characteristic or fairly characteristic radiographic appearance with clinical, historical or serological evidence of rheumatoid disease (31 cases) or (b) characteristic radiographic appearance without evidence of rheumatoid disease ( 9 cases). Probable cases were those who showed a slightly less typical appearance without supporting evidence (10 cases), or doubtful radiographic appearance but with positive clinical or serological evidence (5 cases).

Had it been possible to observe these cases longer, it is likely that several 'probable' cases would have been accepted as 'definite'. The diagnosis of rheumatoid pneumoconiosis is to a large extent radiological; in typical cases a single radiograph suffices, but in others the behaviour of the lesions over a period of time provides support for the diagnosis. In those with a few grouped or unilateral lesions, new nodules may appear to give a more characteristic picture. In others, small nodules may enlarge and become better defined. Others may cavitate and refill. Similarly, arthritis may appear or serological tests may become positive during observation.

CLINICAL AND RADIOLOGICAL FEATURES IN 55 ACCEPTED CASES

Serology Thirty-two cases $(58 \%)$ had a positive test.

Arthritis Eighteen (33\%) were considered to have rheumatoid arthritis (17 'definite' and 1 'probable') ; 14 of these had a positive serological test.

Subcutaneous nodules Five cases (9\%) had nodules at the elbows. All had arthritis and a positive serological test.

Radiographic features In 48 subjects a radiograph taken five years earlier was available for comparison. In 8 cases the nodules were present only on the most recent film. Of the remaining 40,32 showed evidence of progression of the lesions; in seven the lesions had not altered and in one they had regressed. Three cases showing progression also showed regression of some lesions. Cavitation was seen in four, and calcification in some nodules was noted in seven. In 10 cases the lesions, apart from the pneumoconiosis background, were unilateral.

Pleural thickening was apparent in 21 (local, overlying the lesions in nine, distant in 10, and in two cases local and distant thickening).

Age. The average age was 54 years at the time of the first radiographic evidence of rheumatoid pneumoconiosis. In 40 this was at the time of the first survey, and at the time of the second in the remainder. The range was 41 to 64 years. Men of 
65 years or over were not employed at these collieries. Cases conforming to Caplan's original radiographic description ('classical' cases) had a lower average age of 50 years.

Years underground The dust exposure, measured in years of work underground, follows the age distribution. Forty-six had more than 35 years' experience; of these, 17 claimed 45 years or more. Only nine men had worked for less than 35 years underground, and the lowest recorded period was 23 years. Three of these had the classical form with background category 0 . In the East Midlands, with its low incidence of pneumoconiosis, the majority of men with category 1 simple pneumoconiosis have worked for at least 25 years underground.

ANALYSIS OF RESULTS IN COLLIERY SURVEYS The 23 collieries in the survey were labelled alphabetically from $A$ to $W$ in order of rising prevalence of simple pneumoconiosis. Rheumatoid pneumoconiosis has been split into those with lesions including at least one measuring $1 \mathrm{~cm}$. or more ('rheumatoid P.M.F.') and those with all lesions below $1 \mathrm{~cm}$. which can only be fitted into the International Classification (I.L.O., 1959) by allocating them to an appropriate category of simple pneumoconiosis; these are referred to as 'other rheumatoids'. The remaining cases are regarded as having P.M.F. of 'rheumatoid' and 'non-rheumatoid' types.

The incidence of pneumoconiosis at a particular colliery will mean little if there have been considerable manpower changes, and indeed a considerable reduction in manpower had occurred at collieries $\mathbf{K}$ and $\mathbf{N}$. Apart from normal recruitment and retirements, the remaining collieries have not altered substantially for several years. In the two N.C.B. surveys, the numbers of radiographs and the prevalence of pneumoconiosis were very similar. Very few people retired because of rheumatoid or any other kind of pneumoconiosis in this coalfield, and the figures are not distorted by such factors.

Out of a total of 21,557 men who had radiographs, the incidence of rheumatoid pneumoconiosis (55 cases) is $0 \cdot 26 \%$. Definite and probable cases have been considered together in the analysis which follows.

In Figs 1, 2, and 3, total P.M.F., non-rheumatoid P.M.F., and rheumatoid P.M.F. have been plotted against simple pneumoconiosis prevalence. Because of the small number of men affected at any particular colliery there is considerable scatter

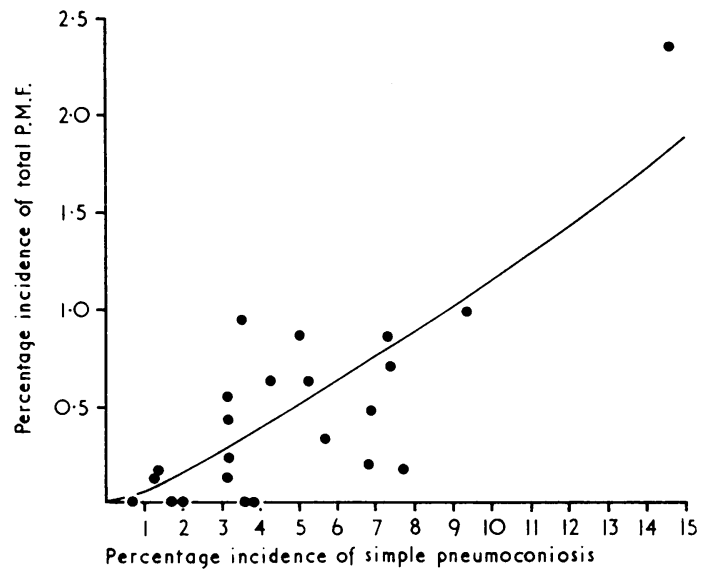

FIG. 1. Scatter diagram of P.M.F. as per cent of men radiographed plotted against simple pneumoconiosis as per cent of men radiographed, in 23 colliery populations.

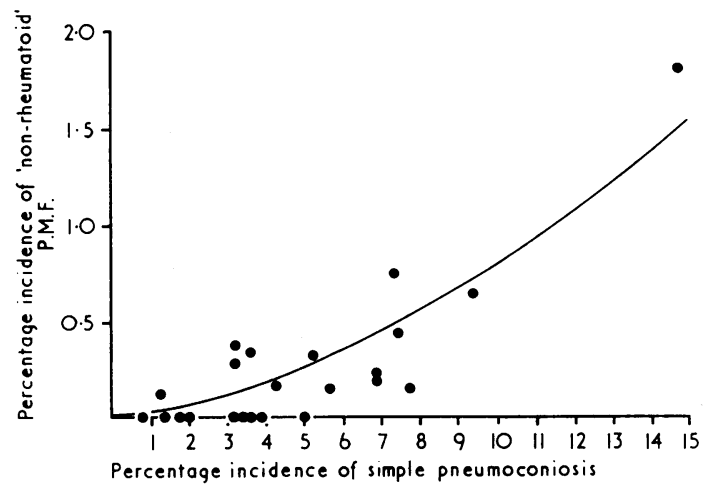

FIG. 2. Scatter diagram of P.M.F. as per cent of men radiographed, after exclusion of rheumatoid cases, plotted against simple pneumoconiosis as per cent of men radiographed, in 23 colliery populations.

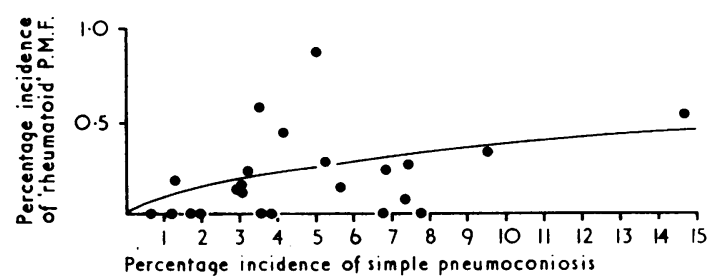

FIG. 3. Scatter diagram of rheumatoid P.M.F. cases as per cent of men radiographed plotted against simple pneumoconiosis as per cent of men radiographed, in 23 colliery populations. 
T A B L E I I I

PREVALENCE OF SIMPLE PNEUMOCONIOSIS, P.M.F., AND RHEUMATOID PNEUMOCONIOSIS: GROUPED COLLIERIES

\begin{tabular}{|c|c|c|c|c|c|c|c|c|c|c|c|c|c|c|c|c|c|c|}
\hline \multirow{3}{*}{ Group ${ }^{1}$} & \multirow{3}{*}{$\begin{array}{c}\text { No. } \\
\text { Radio- } \\
\text { graphed }\end{array}$} & \multicolumn{5}{|c|}{ Simple Pneumnconiosis } & \multicolumn{6}{|c|}{ P.M.F. } & \multicolumn{4}{|c|}{$\begin{array}{c}\text { Rheumatoid } \\
\text { Pneumoconiosis }\end{array}$} & \multirow{2}{*}{\multicolumn{2}{|c|}{$\begin{array}{c}\text { Rheumatoid } \\
\text { Pneumo- } \\
\text { coniosis } \\
\text { with } \\
\text { Positive } \\
\text { Serology }\end{array}$}} \\
\hline & & \multicolumn{3}{|c|}{ Category } & \multicolumn{2}{|c|}{ Total } & \multicolumn{2}{|c|}{$\begin{array}{c}\text { Rheuma- } \\
\text { toid }\end{array}$} & \multicolumn{2}{|c|}{$\begin{array}{l}\text { Non- } \\
\text { rheumatoid }\end{array}$} & \multicolumn{2}{|c|}{ Total } & \multirow{2}{*}{ P.M.F. } & \multirow{2}{*}{ Other } & \multicolumn{2}{|c|}{ Total } & & \\
\hline & & 1 & 2 & 3 & No. & $\%$ & No. & $\%$ & No. & $\%$ & No. & $\%$ & & & No. & $\%$ & No. & $\%$ \\
\hline $\begin{array}{l}1 \\
2 \\
3 \\
4 \\
5\end{array}$ & $\begin{array}{r}2,798 \\
11,056 \\
5,308 \\
908 \\
1,487\end{array}$ & $\begin{array}{r}31 \\
313 \\
264 \\
46 \\
122\end{array}$ & $\begin{array}{r}9 \\
120 \\
111 \\
32 \\
73\end{array}$ & $\begin{array}{r}1 \\
14 \\
13 \\
7 \\
24\end{array}$ & $\begin{array}{r}41 \\
447 \\
388 \\
85 \\
219\end{array}$ & $\begin{array}{r}1 \cdot 5 \\
4 \cdot 0 \\
7 \cdot 3 \\
9 \cdot 4 \\
14 \cdot 7\end{array}$ & $\begin{array}{r}1 \\
29 \\
7 \\
3 \\
8\end{array}$ & $\begin{array}{l}0.04 \\
0.26 \\
0.13 \\
0.33 \\
0.54\end{array}$ & $\begin{array}{r}1 \\
24 \\
22 \\
6 \\
27\end{array}$ & $\begin{array}{l}0.04 \\
0.22 \\
0.41 \\
0.66 \\
1.82\end{array}$ & $\begin{array}{r}2 \\
53 \\
29 \\
9 \\
35\end{array}$ & $\begin{array}{l}0.07 \\
0.48 \\
0.55 \\
0.99 \\
2.35\end{array}$ & $\begin{array}{r}1 \\
29 \\
7 \\
3 \\
8\end{array}$ & $\begin{array}{l}-2 \\
5 \\
-\end{array}$ & $\begin{array}{r}1 \\
31 \\
12 \\
3 \\
8\end{array}$ & $\begin{array}{l}0.04 \\
0.28 \\
0.23 \\
0.33 \\
0.54\end{array}$ & $\begin{array}{r}1 \\
16 \\
9 \\
2 \\
4\end{array}$ & $\begin{array}{l}0.04 \\
0 \cdot 14 \\
0 \cdot 17 \\
0.22 \\
0.27\end{array}$ \\
\hline Total & 21,557 & 776 & 345 & 59 & 1,180 & $5 \cdot 5$ & 48 & 0.22 & 80 & 0.38 & 128 & 0.59 & 48 & 7 & 55 & 0.26 & 32 & 0.15 \\
\hline
\end{tabular}

${ }^{1}$ Group $1,0-2.9 \%$ simple pneumoconiosis (collieries A-E)

Group $2 \quad 3.0-5.9 \%$ simple pneumoconiosis (collieries F-P)

Group $3 \quad 6.0-8.9 \%$ simple pneumoconiosis (collieries Q-U)

Group $4 \quad 9.0-11.9 \%$ simple pneumoconiosis (colliery V)

Group 5 12.0-14.9\% simple pneumoconiosis (colliery W)

T A B L E I V

PROPORTION OF ALL PNEUMOCONIOTICS AFFECTED BY CATEGORY 3 SIMPLE FNEUMOCONIOSIS, P.M.F., AND RHEUMATOID PNEUMOCONIOSIS: GROUPED COLLIERY RESULTS

\begin{tabular}{|c|c|c|c|c|c|c|}
\hline \multirow[b]{2}{*}{ Group ${ }^{1}$} & \multirow[b]{2}{*}{$\begin{array}{c}\text { Total } \\
\text { Pneumoconiosis } \\
\text { (Simple + P.M.F.) }\end{array}$} & \multicolumn{5}{|c|}{ Per cent of Total Pneumoconiosis } \\
\hline & & Category 3 & $\begin{array}{c}\text { Non-rheumatoid } \\
\text { P.M.F. }\end{array}$ & Total P.M.F. & $\begin{array}{c}\text { Rheumatoid } \\
\text { Pneumoconiosis }\end{array}$ & $\begin{array}{c}\text { Rheumatoid } \\
\text { Pneumoconiosis } \\
\text { with Positive } \\
\text { Serology }\end{array}$ \\
\hline $\begin{array}{l}1 \\
2 \\
3 \\
4 \\
5\end{array}$ & $\begin{array}{r}43 \\
500 \\
417 \\
94 \\
254\end{array}$ & $\begin{array}{l}2 \cdot 3 \\
2 \cdot 8 \\
3 \cdot 1 \\
7 \cdot 4 \\
9 \cdot 5\end{array}$ & $\begin{array}{r}2.3 \\
4.8 \\
5.3 \\
6.4 \\
10.6\end{array}$ & $\begin{array}{r}4.7 \\
10.6 \\
7.0 \\
9.6 \\
13.8\end{array}$ & $\begin{array}{l}2 \cdot 3 \\
6 \cdot 2 \\
2 \cdot 9 \\
3 \cdot 2 \\
3 \cdot 2\end{array}$ & $\begin{array}{l}2 \cdot 3 \\
3 \cdot 2 \\
2 \cdot 1 \\
2 \cdot 1 \\
1.6\end{array}$ \\
\hline Total & 1,308 & $4 \cdot 6$ & $6 \cdot 1$ & $9 \cdot 8$ & $4 \cdot 2$ & $2 \cdot 4$ \\
\hline
\end{tabular}

${ }^{1}$ See footnote to Table III.

of individual results, especially in Figure 1 . Although there is a clear trend of increasing total P.M.F. with increasing pneumoconiosis prevalence, the data fit the regression curve much better when rheumatoid cases are excluded (Fig. 2). The relationship of rheumatoid P.M.F. to simple pneumoconiosis is entirely different (Fig. 3): after an initial rise at collieries with extremely low pneumoconiosis prevalence the curve tends to flatten out, so that higher prevalence collieries yield relatively few additional cases. ${ }^{1}$

${ }^{1}$ The regression curves in Figs 1,2 , and 3 have been constructed from the formulae, for Fig. 1: $\log _{\mathrm{e}} \mathrm{p}_{2}=-2.524+1.159 \log _{\mathrm{e}} \mathrm{p}_{1}$; for Fig. 2: $\log _{e} p_{3}=-3.830+1.581 \log _{8} p_{1}$ for Fig. $3: \log _{e} p_{4}=-2.308+0.572 \log _{e} p_{1}$. where $p_{1}$ is the prevalence of simple pneumoconiosis $\%$, $p_{2}$ the percentage of total P.M.F., $p_{3}$ the percentage of non-rheumatoid P.M.F., and $p_{4}$ the percentage of rheumatoid P.M.F. For Fig. 1 the fit of the data is poor $\left(\chi^{2}=26.5\right.$ with 9 degrees of freedom $0.01>P>0.001$ ), but for non-rheumatoid P.M.F. and rheumatoid P.M.F. it is quite satisfactory $\left(x^{2}=8.49\right.$ with 7 degrees of freedom. $P=0.3$ and $\chi^{2}=7.83$ with 5 degrees of freedom, $P=0.2$ respectively)
It would have been more satisfactory had more collieries with a high pneumoconiosis prevalence been available for study. That they were not is due to the low general prevalence in the East Midlands; colliery $\mathrm{W}$ has in fact the highest prevalence in this coalfield. Further observations might well have altered the curves.

In Table III the collieries have been grouped according to the prevalence of pneumoconiosis. The trends shown in Figs 1 to 3 are clearly evident. The total prevalence of rheumatoid pneumoconiosis and that of the P.M.F. type increases slowly with increasing prevalence of pneumoconiosis; the prevalence of non-rheumatoid P.M.F. increases more steeply.

In Table IV the total number of patients with pneumoconiosis of all kinds are shown for each group of collieries. Both category 3 simple pneumoconiosis and non-rheumatoid P.M.F. show a similar rise in proportion of total pneumo- 
T A B L E V

P.M.F. AND RHEUMATOID PNEUMOCONIOSIS ANALYSED BY BACKGROUND CATEGORY OF PNEUMOCONIOSIS

\begin{tabular}{|c|c|c|c|c|c|c|c|c|c|}
\hline \multirow{3}{*}{$\begin{array}{l}\text { Radiological } \\
\text { Category }\end{array}$} & \multirow{3}{*}{$\begin{array}{l}\text { Total No. of Men } \\
\text { in Each Category } \\
\text { (Simple+P.M.F.) }\end{array}$} & \multicolumn{6}{|c|}{ P.M.F. } & \multirow{2}{*}{\multicolumn{2}{|c|}{$\begin{array}{l}\text { Total Rheumatoid } \\
\text { Pneumoconiosis }\end{array}$}} \\
\hline & & \multicolumn{2}{|c|}{ Rheumatoid } & \multicolumn{2}{|c|}{ Non-rheumatoid } & \multicolumn{2}{|c|}{ Total } & & \\
\hline & & No. & $\%$ & No. & $\%$ & No. & $\%$ & No. & $\%$ \\
\hline $\begin{array}{l}0 \\
1 \\
2 \\
3\end{array}$ & $\begin{array}{r}20,253 \\
806 \\
408 \\
90\end{array}$ & $\begin{array}{r}4 \\
16 \\
26 \\
2\end{array}$ & $\begin{array}{l}0.02 \\
1.99 \\
6.37 \\
2.22\end{array}$ & $\begin{array}{l}\overline{14} \\
37 \\
29\end{array}$ & $\begin{array}{r}\overline{1.74} \\
9.07 \\
32.22\end{array}$ & $\begin{array}{r}4 \\
30 \\
63 \\
31\end{array}$ & $\begin{array}{r}0.02 \\
3.72 \\
15.44 \\
34: 45\end{array}$ & $\begin{array}{r}5 \\
22 \\
26 \\
2\end{array}$ & $\begin{array}{l}0 \cdot 02 \\
2 \cdot 73 \\
6 \cdot 37 \\
2 \cdot 22\end{array}$ \\
\hline Total & 21,557 & 48 & 0.22 & 80 & 0.38 & 128 & 0.59 & 55 & $0 \cdot 26$ \\
\hline
\end{tabular}

coniosis on going from the low to the high prevalence collieries. The prevalence of rheumatoid pneumoconiosis, and especially that with positive serology, shows no such increase, and the proportion of all cases of pneumoconiosis affected by rheumatoid pneumoconiosis remains constant throughout these groups.

PNEUMOCONIOSIS BACKGROUND In Table $\mathrm{V}$ P.M.F. and rheumatoid cases have been split according to the background category of simple pneumoconiosis. This shows a marked contrast between non-rheumatoid P.M.F. and rheumatoid cases, the former being, associated with a high background in the majority, whereas nearly half the rheumatoids have a background of category 0 or 1 . The likelihood of massive shadows developing increases from a very small number in category 0 to one-third of all men affected in category 3. Among those in category 1 who develop massive shadows, more than half are of rheumatoid type, and about one-third in category 2 . In category 3, however, the overwhelming number are non-rheumatoid.

For rheumatoid pneumoconiosis there is a rising incidence from category 0 to category 2 and an apparent fall in category 3 . This is discussed later.

GEOGRAPHICAL ANALYSIS The proportion of rheumatoids, as a percentage of all men with pneumoconiosis, is really remarkably uniform except for Mansfield. Some patients were known to us at the Mansfield Clinic and it is impossible to deny an unconscious bias in including some with negative serological tests who might otherwise have been rejected because of insufficient evidence. The small excess of serologically positive cases is not significant statistically.

\section{DISCUSSION}

Possible factors in the aetiology of P.M.F. have been investigated by Cochrane (1962). The only factor found to influence the attack rate of P.M.F was the background of simple pneumoconiosis; the chances of P.M.F. developing increase from about $1 \%$ for category 1 to $30 \%$ or more for category 3. He found no epidemiological evidence to support the tuberculous hypothesis which for many years was considered the most likely explanation. This view was supported by the production in experimental animals of nodular lesions by combined injections of various dusts with tubercle bacilli of low virulence (King, Yoganathan, Harrison, and Mitchison, 1957). That such an effect is not infective in nature has been shown by the production of similar lesions with dead bacilli (Attygalle, Harrison, King, and Mohanty, 1954), and with P.P.D. tuberculin (Gross, 1960) and by the failure of antituberculosis treatment to influence P.M.F. in coal miners (Rogan, 1963). The possibility that the mechanism is immunological rather than infective has been developed by Vigliani and Pernis (1958) and Pernis (1963). They postulate that mineral dust, in producing cellular damage, releases abnormal protein substances from cells and that an auto-immune reaction develops to these in a proportion of subjects. Such subjects then develop fibrohyaline lesions. They suggest that the part played by tuberculosis in the experimental studies is similar to the use of Freund's adjuvant. Although silica has been used in experimental work, the theory may equally well apply in other forms of pneumoconiosis. The recognition of an association between rheumatoid arthritis, an accepted autoimmune disease, and pneumoconiosis gives some support to the hypothesis.

One difficulty in accepting the auto-immune hypothesis is the finding that the attack rate of P.M.F. is related to the background category of simple pneumoconiosis. The latter is related to the weight of dust in the lungs (Rivers, Wise, King, and Nagelschmidt, 1960). The reaction therefore appears to be related not only to the presence of an antigen (the result of cell damage produced by 
dust) but also to its amount. There would be a serious objection if the mechanism were allergic, but it does not rule out an immunological process (Vigliani and Pernis, 1958); these authors point out that in the experimental production of amyloidosis with casein-Na, relatively large doses of this protein are necessary. It should be noted that the weight of dust in lungs with massive lesions is not necessarily greater than in lungs with category 3 simple pneumoconiosis (Rivers et al., 1960 ; King, Maguire, and Nagelschmidt, 1956).

Thus there may be two factors involved in the aetiology of P.M.F. - the quantity of dust in the lungs and the immune response of the individual. In a situation where two factors operate it should be possible to define a spectrum embodying the pure effect of one factor at each end with a gradation of mixed causation between. At one end of the spectrum we have a high dose and apparently no auto-immune predisposition; these are men with category 3 simple pneumoconiosis and no evidence of development of P.M.F. At the other end are cases with rheumatoid nodules in the lungs but without evidence of dust exposure (Noonan, Taylor, and Engleman, 1963). In between are all those cases with nodular shadows of one type or another representing the combined result of coal dust (slightly fibrogenic) on the one hand and auto-immune disturbance on the other. The appearances of P.M.F. as a gradual development from a heavy dust background would be the result of high dose with low, but not absent, immune response to the damage caused by the dust. The auto-immune state is too slight to be detected by ordinary clinical methods. Classical rheumatoid pneumoconiosis is the expression of a high auto-immune disturbance in which the presence of some dust precipitates the appearance of nodules in the lungs, differing histologically from P.M.F. In both situations, however, it could be expected that the likelihood of massive shadows developing is increased when simple pneumoconiosis is more marked. The number who develop the classical rheumatoid type, however, will be limited by the number of men in the population with a sufficiently strong rheumatoid predisposition, whereas ordinary P.M.F. may be expected to go on increasing as simple pneumoconiosis increases. Cases intermediate between classical rheumatoid pneumoconiosis and P.M.F. can be expected; as the dose of dust increases conditions become suitable for those with an intermediate degree of autoimmunity to develop massive shadows. The association with clinical rheumatoid disease and the presence of positive tests for rheumatoid factor will be less clear-cut than in classical cases ; and, as the dose of dust and the immunological disturbance play joint but variable roles, the predominance of one or the other will influence the radiographic appearance of the lesions, their behaviour in time, and their morbid anatomical features.

In this study we have used the prevalence of simple pneumoconiosis in a colliery population as an index of the dose of dust. In group 1 collieries (Table 1II), the only case of rheumatoid pneumoconiosis had no background of simple pneumoconiosis and the lesions conformed to Caplan's original radiological description. In the group 5 colliery there was no such case, and six out of the eight men with rheumatoid pneumoconiosis had mixed nodular and irregular opacities as described by Caplan et al. (1962). Five of these had a background of category 2 and one of category 1 simple pneumoconiosis. In this type we consider that a higher dose of dust is often implicated and that this influences the radiographic appearance and the behaviour of the lesions. Fewer of these cases will have arthritis or positive serological tests.

In individual cases the dose of dust is reflected by the background of simple pneumoconiosis. Table $\mathrm{V}$ shows a rising prevalence of rheumatoid pneumoconiosis from category 0 to category 2 with an apparent fall in category 3 . If not due to chance, there may be two reasons for this. First, scanty small nodules which, with a low or absent background might be recognizable as rheumatoid, may blend into the heavy background. Secondly, the higher dose of dust may cause rheumatoid nodules to progress more readily and more quickly into a state indistinguishable from ordinary P.M.F.

Table III shows a tendency for the prevalence of rheumatoid pneumoconiosis to rise with increasing simple pneumoconiosis prevalence in the groups of collieries (although the rise is too slight to be significant statistically). Of men with pneumoconiosis (Table IV) the proportion of rheumatoid cases lay between $2 \cdot 3 \%$ and $6.2 \%$, and of those with serologically positive tests between $1.6 \%$ and $3.2 \%$. In a study of the epidemiology of the sheep cell agglutination test, Ball and Lawrence (1961) found positive tests in between $1.6 \%$ and $5.4 \%$ of subjects in seven European population samples in the age range 55 to 64 years. Most of our cases were aged between 50 and 64 years. It is evident that the occurrence of rheumatoid pneumoconiosis among pneumo- 
coniotics is somewhat similar to the proportion of the general population with detectable rheumatoid factor. Since in the presence of a heightened tendency to auto-immune reactions nodular lesions may develop with a lower dose of dust, the background category in rheumatoid cases is lower than in ordinary P.M.F.

This has of necessity been a study of collieries with a low pneumoconiosis prevalence. No information is available on the relationships which would obtain at collieries with a great deal of pneumoconiosis. We would expect results along the following lines. In collieries with a very low prevalence of simple pneumoconiosis, very few cases with large opacities can be expected, and all or nearly all will be of rheumatoid type, usually the classical form. Because relatively few men reach category 2 and very few reach category 3 during their working lives, the chances of P.M.F. developing will be small (Cochrane, 1962), so that only those with a marked auto-immune disturbance will develop large shadows. In collieries with more pneumoconiosis the number of rheumatoid cases will be increased, a greater proportion being of atypical form and less often accompanied by arthritis or positive serological tests; at the same time ordinary P.M.F. will appear in an increasing proportion of men with complicated pneumoconiosis. In collieries with a large amount of pneumoconiosis there will be many large opacities, the vast majority being ordinary P.M.F. Classical areas of rheumatoid pneumoconiosis will still occur and be recognizable, particularly in younger men and those less affected by dust ; atypical cases will also be found, but usually with a higher background category and increasingly difficult to differentiate from ordinary P.M.F., especially in older age groups. This may give an impression that the prevalence of rheumatoid pneumoconiosis is lower than at less dusty collieries, where the dust component is less and cases are more easily recognized. Our particular awareness of rheumatoid pneumoconiosis is due to the low level of pneumoconiosis in the East Midlands, where it forms a substantial proportion of all large opacities.

The number of rheumatoid pneumoconiosis cases will also be influenced by the amount of rheumatoid disease in the community. This does vary in different localities (Miall, 1955). In this series there seemed to be an excess of cases in the
Mansfield area, but this was not statistically significant when sero-positive cases only were considered. No information is available on the $\frac{\bar{m}}{7}$ total prevalence of rheumatoid arthritis in the $\stackrel{\mathbb{D}}{\mathscr{Q}}$ area.

We are grateful to Dr. J. M. Rogan, Chief Medical Officer, National Coal Board, for permission to publish this paper, and to Dr. J. Trefor Watkins, East Midlands Divisional Medical Officer, National Coal Board, who provided facilities for this investigation. Serological examinations were undertaken by Dr. N A. C. K. Lawrence and Dr. H. M. Rice. Statistical o analysis was carried out by Mr. F. Holme. To these of and to the chest physicians and National Coal Board $\mathrm{G}$ Area Medical Officers, who co-operated in a variety 윽 of ways, we are greatly indebted. We are also grateful to Mrs. R. P. Bee and Miss B. Buck for secretarial $Z$ assistance.

\section{REFERENCES}

American Rheumatism Association (1959). 1958 revision of diagnostic criteria for rheumatoid arthritis. Arthr. and Rheum., 2, 16.

Attygalle, D., Harrison, C. V., King, E. J., and Mohanty, G. P. (1954). Oా Infective pneumoconiosis. I. The influence of dead tubercle bacilli (BCG) on the dust lesions produced by anthracite, coalmine dust, and Kaolin in the lungs of rats and guinea-pigs. Brit. J. industr. Med., 11, 245.

Ball, J., and Lawrence, J. S. (1961). Epidemiology of the sheep cell agglutination test. Ann. rheum. Dis., 20, 235.

Caplan, A. (1953). Certain unusual radiological appearances in the 응 chest of coal-miners suffering from rheumatoid arthritis. Thorax, 8, 29

- Payne, R. B., and Withey, J. L. (1962). A broader concept of Caplan's syndrome related to rheumatoid factors. Ibid., 17, 205.

Cochrane, A. L. (1962). The attack rate of progressive massive 윽 fibrosis. Brit. J. industr. Med., 19, 52 Gross, P. (1960). An immunologic approach to the pneumoconioses.
Arch. industr. Hlth, 21, 228.

International Labour Organisation (1959). Meeting of experts on the international classification of radiographs of the pneumoconioses. Occup. Safety Hlth, 9, 63.

King, E. J., Maguire, B. A., and Nagelschmidt, G. (1956). Further studies of the dust in lungs of coal-miners. Brit. J. industr. Med., $13,9$.

- Yoganathan, M., Harrison, C. V., and Mitchison, D. A. (1957). Experimental infective pneumoconiosis. Arch. industr. Hith, 16, 380 .
Experimental infective pneumos

Miall, W. E. (1955). Rheumatoid arthritis in males. An epidemio- 윽 logical study of a Welsh mining community. Ann. rheum. Dis., $14,150$.

_Caplan, A., Cochrane, A. L., Kilpatrick, G. S., and Oldham, P. D. (1953). An epidemiological study of rheumatoid arthritis $D$ associated with characteristic chest $x$-ray appearances in coal- $C$ workers. Brit. med. J., 2, 1231.

Noonan, C. D., Taylor, F. B., and Engleman, E. P. (1963). Nodular $N$ rheumatoid disease of the lung with cavitation. Arthr. and $\sigma$ Rheum., 6, 232 .

Pernis, B. (1963). Immunohistochemical observations on the human $\mathrm{N}$ silicotic nodule. Med. d. Lavoro, 54, 354.

Rivers, D., Wise, M. E., King, E. J., and Nagelschmidt, G. (1960). $\omega$ of coal-workers. Brit. J. industr. Med., 17, 87.

Rogan, J. M. (1963). Annual Report for the year 1963. Medical service and medical research. National Coal Board, London.

Vigliani, E. C., and Pernis, B. (1958). Immunological factors in the $\mathscr{C}$ pathogenesis of the hyaline tissue of silicosis. Brit. J. industr. Med., 15, 8. 